\title{
Notas sobre a escola unitária e trabalho no pensamento de Antonio Gramsci
}

Jefferson Carriello do Carmo ${ }^{1}$

Resumo: O objetivo do texto é tecer algumas notas sobre a escola unitária e o trabalho, no Caderno 12, de Antonio Gramsci. O filósofo sardo introduz, nesse caderno, o tema dos intelectuais através das instituições especializadas, a proposta escolar no contexto da crise da escola tradicional das "novas" exigências de trabalho, postas pela industrialização e pela reforma de Giovani Gentile. Para Gramsci, a escola unitária não representa nem um saudosismo humanista tradicional nem um profissionalismo tecnicista, mas um novo tipo de escola interessada. Em outras palavras, uma escola mais técnica e mais orgânica em relação ao mundo industrial moderno, baseada em princípios científicos e tecnológicos, constituída num espaço de síntese entre a prática e a teoria, entre o trabalho manual e o intelectual.

Palavras-chaves: Itália, crise escolar, industrialização, escola unitária Antonio Gramsci

Abstract: The goal of the text is make some notes on the school and the work unit, in the terms twelve, Antonio Gramsci. Whereas, in principle, which the philosopher Sardinian introduces this book, the theme of intellectuals through specialized institutions and the examination of the proposed school in the context of the crisis of the traditional school of "new" demands of work made by industrialization and the reform of Giovanni Gentile. To Gramsci the school unit is not a traditional or a humanist saudosism technicist professionalism, but a new type of school concerned. In other words, a school more technical and more organic in relation to the modern industrial world, based on scientific principles and technology, made in an area of synthesis between the theory and practice, between the manual and intellectual work.

Keywords: Italy, education crisis, industrialization, unitary school, Antonio Gramsci

1 Prof. Dr. da Universidade de Sorocaba. Correio eletrônico: jeffccprof@gmail.com

cadernos cemarx, $\mathrm{n}^{\circ} 5-2009 \quad 53$ 


\section{Introdução}

As formulações gramscianas sobre escola única, tendo no trabalho o princípio educativo, estão inseridas no Caderno de número 12, cuja estrutura está composta por três textos. O primeiro centra-se na teoria geral a respeito da produção histórica dos intelectuais e da escola como instituição própria que forma os intelectuais. Aqui, a noção de escola refere-se a todo tipo de organização cultural para a formação dos intelectuais, sendo que estas organizações são criadas e sustentadas historicamente pelas diferentes práticas ou forças produtivas da sociedade. A segunda está na relação orgânica da escola com a sociedade tradicional do passado, nos seus aspectos cotidianos e históricos, na qual Gramsci constata o caráter "desinteressado" da escola. Mostra que o ensino das línguas greco-latinas na escola tradicional não era um ensino "profissionalizante", no sentido "interessado", e sim "formativo-desinteressado". No ensino do grego e do latim não se pressupunha o uso e necessidade imediatos, mas assimilar valores ético-culturais das civilizações que falavam aquelas línguas e, ao mesmo tempo, para adquirir mecanismos lógicos e habilidades técnicas próprias da gramática. Na terceira formulação, o filósofo sardo parte da crise pedagógica da escola tradicional e entende que não houve resposta adequada, por parte da pedagogia moderna ativa, às transformações sócio-econômicas que estavam ocorrendo na Itália após a Primeira Guerra Mundial, o que o remete a indicar, em princípio, a "escola" do Partido que representava a classe social historicamente emergente envolvida por uma civilização moderna do trabalho industrial e técnico (GRAMSCI, 2000, p.15-53). Esse tratamento que Gramsci dá a escola unitária tendo o trabalho como principio educativo vincula-a, também, ao Partido Comunista Italiano, tendo como referência a crise italiana e a Reforma Educacional² de Giovanni Gentile (CARMO, 2001).

2 Com a expressão "Reforma Educacional", refiro-me à sua estrutura e ao complexo de decretos-leis e de normas provenientes de Giovanni Gentile, primeiro ministro da pública instrução, no período fascista, de 30 de outubro de 1922 a 26 de junho de 1924. De forma geral, essa reforma foi fixada em um plano legislativo, mediante uma série de leis separadas, mas que idealmente estavam unidas em uma visão integral dos problemas da escola, da cultura e do trabalho. A exemplo, citamos três leis, R.D. maio de 1923, n.1054, Regulamentação da Instrução Média e dos Colégios Nacionais, R.D. 30 setembro de 1923, n. 2102, Regulamentação da Instrução superior; D. $1^{\circ}$ outubro de 1923, n. 2185, Regulamento das grades escolares e dos programas didáticos de instrução elementar. Essas leis foram acompanhadas por uma abundância de circulares contendo instruções para dirigir a conduta dos órgãos dependentes do Ministério da Educação no que se refere à interpretação e à aplicação da reforma. Dentre essas circulares estava a de 25 de novembro de 1922, cujo conteúdo se refere à "autoridade na escola", que tinha por objetivo a ordem, a disciplina e a obediência da escola ao Estado, garantidas por um conjunto de instruções que seriam o fundamento da convivência civil. Dentre esse conjunto de instruções, estava a proposta da escola profissional, que era nitidamente diferenciada das outras e visava formar habilidades meramente utilitárias em seus destinatários. O programa educacional proposto por Gentile não só limita o acesso à educação completa de todos, mas divorcia a atividade manual da intelectual, reforçando a divisão social do trabalho. Cf. BELLUCCI, Maria; CILIBERTO, Michele. La scuola e la pedagogia del fascismo. Torino: Loescher Editore, 1978; BORGHI, Lamberto.

54 Notas sobre a escola unitária e trabalho no pensamento de Antonio Gramsci 
Embora o tema que introduz o Caderno 12 seja o dos intelectuais através das instituições especializadas, a escola é o nosso objeto de estudo, delimitado no momento em que Gramsci se detém mais demoradamente no exame da proposta de escola unitária no contexto das relações entre a escola e o trabalho, em que a crise da escola tradicional contrai-se pela "nova" industrialização (MANACORDA, 1990), de um lado e pela Reforma de Giovani Gentile, de outro (GRAMSCI, 1972).

\section{Escola Única - Escola para o trabalho}

O background pelo qual Gramsci vê a escola única para o trabalho são as novas exigências postas pela industrialização e formação do homem (GRAMSCI, 1972). Indica que o princípio escolar deve ser a solução da crise através da integração entre cultura e trabalho, cuja finalidade é o equilíbrio justo entre a "capacidade de trabalhar manualmente (tecnicamente, industrialmente) e o desenvolvimento das capacidades de trabalho intelectual" (GRAMSCI, 2000, p.33).

Neste encaminhamento, Gramsci irá fazer o debate educacional em cujo contexto está a disputa entre o capital e o trabalho, no âmbito do Estado para, finalmente, propor uma nova e original alternativa ${ }^{3}$ para a educação da classe trabalhadora, evitando qualquer tipo de conciliação oportunista. Defende uma escola desinteressada do trabalho, essencialmente humanista, com atividades formativoculturais para o conjunto do proletariado, segundo Nosella,

Será uma das idéias-chave até o final de sua vida. O homem renascentista, para ele, sintetiza o momento de elevada cultura com o momento de transformação técnica e

Educazione e autorità nell' Italia moderna. Firenze, La Nuova Italia editore, 1975..

3 Entendemos que Gramsci irá resgatar as várias perspectivas pedagógicas divergentes no encaminhamento da classe operária a uma educação integral. Segundo as palavras de Andreucci (1992), já existiam em vários países da Europa organizações escolares mantidas pelo movimento operário desde 1886. Nessa construção, ainda que diferenciada, para encaminhar o trabalhador a uma educação integral, surgem os anarquistas. Sua pedagogia tinha por objetivo desenvolver no educando todas as possibilidades nos aspectos mental, físico, intelectual ou afetivo e integrá-lo em todas as atividades sociais, tendo como finalidade a revolução social. Sob a ótica marxista (Marx e Engels nunca escreveram um texto específico sobre escola e educação, porém encontramos, desde os Manuscritos até $O$ capital, questões esparsas sobre o assunto), temos algumas considerações sobre a questão escolar, que tem seu eixo no trabalho produtivo e na divisão social, no âmbito da fábrica. Ao constatar esses fato e suas conseqüências para o trabalhador, propõe uma educação politécnica, isto é, a combinação entre trabalho produtivo e educação mental, exercícios corporais e aprendizagem politécnica. Para um estudo mais detalhado sobre as várias pedagogias que visam a uma educação integral, embora divergentes, consultar os seguintes autores: BAKUNIN, M. La instrucción integral. Madri: Scriptorius, 1979. TOMASI, Tina. Ideología libertarie e formazione umana. Firenze: La nuova Italia , 1973. RAYNAUD, J. M; AMBAUVES, G. L' education libertaria. Paris: Spartacus, 1978. Maurice. Os grandes socialistas e a educação: de Platão a Lenine. Lisboa: Europa-America, 1974. MARX, Karl e ENGELS, Friedrich. Crítica da educação e do ensino. Introdução e notas de Roger Dangeville. Lisboa Portugal: Moraes, 1978.

cadernos cemarx, $\mathrm{n}^{\circ} 5-2009 \quad 55$ 
artística da matéria e da natureza; sintetiza também a criação das grandes idéias teórico-

políticas com a experiência da convivência popular. Gramsci sintetiza, no ideal da escola moderna para o proletariado, as características da liberdade e livre iniciativa individual com as habilidades necessárias à forma produtiva mais eficiente para a humanidade de hoje, concebendo um projeto educacional distinto tanto da concepção humanista do renascimento quanto da concepção pragmática e racionalista da era capitalista. Para ele, esses dois pólos são organicamente interdependentes (NOSELLA, 1992, p. 20).

Tal escola, na compreensão do filósofo, não deveria estar presa a uma concepção de mundo idealista, típico de programas escolares escolásticos, que não consegue elaborar uma cultura que desse conteúdo moral e científico aos que permanecem nesse esquema abstrato e teórico. A proposta de Gramsci de uma escola desinteressada do trabalho ${ }^{4}$, seria baseada na filosofia da práxis; seria o coroamento de todo um movimento de reforma intelectual e moral e estaria contrapondo, dialeticamente, os princípios da cultura proletária e da cultura burguesa.

Da mesma forma, o conceito de escola desinteressada do trabalho, como escola unitária, diferencia-se da escola do trabalho por não se preocupar em satisfazer interesses imediatos, nem em proporcionar a aquisição de habilidades operacionais para a produção industrial e por não ser uma escola do emprego. A escola desinteressada do trabalho coincide com a escola do trabalho apenas por fundamentar seu processo de ensino/aprendizagem na aplicação direta e objetiva da ciência e da tecnologia em processos produtivos. Segundo Gramsci, o seu surgimento significa "o início de novas relações entre trabalho intelectual e trabalho industrial não apenas na escola, mas em toda a vida social. O princípio unitário, por isso, irá se refletir em todos os organismos de cultura, transformando-os e emprestando-lhes um novo conteúdo" (GRAMSCI, 2000:, p. 40).

Nesta citação, Gramsci reafirma a sua preocupação central em integrar a corrente humanista e a profissional que se chocam no campo do ensino do proletariado, lembrando que, antes do operário, existe o homem que, embora subjugado pela máquina, não deve ser impedido de percorrer os mais amplos horizontes do espírito.

\footnotetext{
4 Segundo Nosella (1992:20), "Gramsci utiliza com extrema freqüência essa expressão, desde seus primeiros escritos políticos (1914), até os últimos Cadernos: cultura "desinteressada", escola "desinteressada", Partido "desinteressado" etc. Desinteressado não quer dizer neutro ou interclassista. E uma expressão difícil de traduzir para a língua portuguesa e, mesmo em língua italiana, esse termo, tomado em abstrato, não traduz o sentido que Gramsci lhe dá. Por isso, freqüentemente ele mesmo põe o termo entre aspas e quase sempre tenta explicitá-lo: desinteressado é o que não é imediata e individualmente utilizável, mas que é útil a muitos, a toda coletividade, historicamente e objetivamente, a longo alcance". 
Em resumo, a escola desinteressada do trabalho, ou a Escola Única, não representa um saudosismo humanista tradicional nem um profissionalismo tecnicista. A proposta de Escola Única resgata o potencial educativo da escola humanista tradicional, em confronto com a necessidade de um novo tipo de escola mais interessada, propondo uma escola mais técnica e mais orgânica em relação ao mundo industrial moderno, baseada em princípios científicos e tecnológicos e que se constitua num espaço de síntese entre a prática e a teoria, entre o trabalho manual e o intelectual.

Tal proposta, esclarece Nosella (1992), está centrada na idéia da liberdade concreta, universal e historicamente obtida, isto é, na liberdade gestada pelo trabalho industrial e universalizada pela luta política. A relação escola/trabalho dá sentido à idéia de liberdade.

É notável que, através da investigação do Americanismo e do Fordismo, Gramsci aponta "soluções racionais" para a sociedade. No fordismo, se depara com aspectos que, em sua compreensão, são essenciais para o desenvolvimento da humanidade (GRAMSCI, 2001).

Na compreensão de Gramsci, o desenvolvimento produtivo, advindo das forças produtivas e das relações de produção capitalistas inerentes ao fordismo, é suficiente para transformar as relações sociais e políticas e, até mesmo, formar uma nova sociedade industrial, técnica e cientifica. Em Animalidade e industrialismo, esclarece:

A história do industrialismo foi sempre (e se torna hoje de modo ainda mais acentuado e rigoroso) uma luta contínua contra o elemento "animalidade" do homem, um processo ininterrupto, freqüentemente doloroso e sangrento, de sujeição dos instintos (naturais, isto é, animalescos e primitivos) a normas e hábitos de ordem, de exatidão, de precisão sempre novos, mais complexos e rígidos, que tornam possíveis as formas cada vez mais complexas vida coletiva, que são a conseqüência necessária do desenvolvimento do industrialismo. Esta luta é imposta a partir de fora e os resultados obtidos até agora, embora de grande valor prático imediato, são em grande parte puramente mecânicos, não se transformaram numa "segunda natureza” (GRAMSCI, 2001, p. 262).

Segundo Nosela (1992), essa compreensão de Gramsci do americanismo tem um significado histórico relevante no sistema produtivo por indicar a condição real para uma nova civilização que exige do homem um conhecimento de novo tipo, no qual a teoria e a prática se conformam a uma unidade, o que possibilita um novo

cadernos cemarx, $\mathrm{n}^{\circ} 5-2009 \quad 57$ 
humanismo, um novo tipo de relação entre conhecimento e trabalho. Enfatiza que o modo de produção trata apenas de uma fase superior de um processo que não é novo e inicia-se com a industrialização, abrindo novas possibilidades para a classe trabalhadora.

Para o capital, a descoberta e a aplicação da imaginação nos diferentes processos produtivos e a "liberação" do cérebro do operário para novas disponibilidades de energias humanas trouxeram preocupações e interesses político-econômicos. $\mathrm{Na}$ ótica do capital, esclarece Gramsci, essa descoberta foi ocupada pela produção integral da liberdade, mas em favor da produção de mais-valia (GRAMSCI, 2001, p. 272).

Podemos inferir, à luz da citação, que essa problemática levantada por Gramsci pode ser entendida como uma das propostas da escola unitária, que surge exatamente do fato de os industriais se preocuparem em ocupar os cérebros dos trabalhadores livres da produção através de "escolas" fundamentadas na máquina ou na ciência, metafisicamente e não historicamente. Através da proposta de Escola unitária, Gramsci contrapõe a concepção de educação idealista, através das proposições marxianas de prática produtiva como ponto de partida.

Essa proposta pode ser vista através dos Cadernos do Cárcere e das suas Cartas, quando tornam evidente que o prisioneiro do regime fascista tinha grandes preocupações com as questões didático-pedagógicas sob a ótica do trabalho. Tal pensamento educacional tinha o interesse oposto a uma formação de um técnico abstrato, um intelectual desenraizado das suas origens, concebido pela ótica do capital, que vinha se tornando uma ameaça para a aliança revolucionária:

Pode-se observar, em geral, que na civilização moderna todas as atividades práticas se tornaram tão complexas, e as ciências se mesclaram de tal modo à vida, que cada atividade prática tende a criar uma escola para os próprios dirigentes e especialistas e, conseqüentemente, tende a criar um grupo de intelectuais especialistas de nível mais elevado, que ensinem nestas escolas. Assim, ao lado do tipo de escola que poderíamos chamar de "humanista" (e que é o tipo tradicional mais antigo), destinado a desenvolver em cada indivíduo humano a cultura geral ainda indiferenciada, o poder fundamental de pensar e de saber orientar-se na vida, foi-se criando paulatinamente todo um sistema de escolas particulares de diferentes níveis, para inteiros ramos profissionais ou para profissões já especializadas e indicadas mediante uma precisa especificação. (GRAMSCI, 2000, p. 32-33)

58

Notas sobre a escola unitária e trabalho no pensamento de Antonio Gramsci 
Se existe na sociedade moderna industrial um programa novo de organização de escola, Gramsci é da opinião que deveria haver um novo tipo de intelectual.

Essas preocupações estão expressas em uma de suas cartas a Giulia, sua esposa, na qual aponta para a necessidade de uma educação "não" espontânea, que deveria começar já na tenra idade, pois, para ele, as fantasias da criança, sua inteligência e seu desenvolvimento são realidades históricas:

Creio que em cada um deles subsistem todas as tendências, como em todos os meninos, quer seja em relação à teoria ou à fantasia, e que antes seria justo guiá-los, neste sentido, para uma adaptação harmoniosa de todas as atividades intelectuais e práticas, que terão meios de se especializar ao seu tempo com base numa personalidade vigorosamente formada no sentido da totalidade e integral. O homem moderno deveria ser uma síntese daqueles que se tornam união hipostática dos caracteres nacionais: o engenheiro americano, o filósofo alemão, o político francês, recriando, por assim dizer, o homem italiano do Renascimento, o tipo moderno de Leonardo da Vinci tornado homem massa ou homem coletivo mesmo mantendo a sua forte personalidade e originalidade individual (GRAMSCI, 1996, p. 300).

Tendo em vista o desenvolvimento harmonioso e integral do indivíduo, Gramsci tem por preocupação mostrar a sua rejeição por qualquer idéia de espontaneismo pedagógico porque respeita profunda e historicamente a criança como cidadão em formação e pensa o indivíduo no contexto das relações de produção capitalista.

Gramsci é contra toda concepção heterônoma e contra toda concepção autônoma da relação educativa. Isso porque o homem possui uma formação histórica; é uma criação transcendente. A afirmação é suscetível de uma formação unilateral e, para que isso não venha ocorrer, o aluno deve ter uma participação ativa na escola e a escola deve estar ligada à vida. Nesse sentido, esclarece Manacorda, "a consciência da criança é o reflexo da sociedade civil de que participa e o dado racional e subjetivo através do qual a educação se configura como uma 'coação' ou 'coletivização' inevitavelmente 'dogmática', mesmo que fundamenta sobre a participação ativa e criadora do educando." (MANACORDA, 1966, p. 124)

Essas considerações irão viabilizar a proposta de organização escolar que vai ser denominada escola unitária, cujo objetivo é o desenvolvimento de todas as potencialidades da criança e "deveria assumir a tarefa de inserir os jovens na atividade

cadernos cemarx, $\mathrm{n}^{\mathrm{o}} 5-2009 \quad 59$ 
social, depois de tê-los elevado a um certo grau de maturidade e capacidade para a criação intelectual e prática e a uma certa autonomia na orientação e na iniciativa" (GRAMSCI, 2000, p. 36).

O tempo de duração dessa escola é proposto por Gramsci em um primeiro momento para as crianças de 3 a 4 anos de idade, o que equivaleria ao Ensino Básico. Inclui a escrita, a noção de matemática e as primeiras noções de Estado e Sociedade ( GRAMSCI, 2000, p. 37).

Nessa primeira fase, Gramsci tem a consciência de que deve existir uma ação pedagógica, cujo objetivo é modelar e fecundar a orientação dogmática para, somente numa segunda fase, de cinco a seis anos, adotar uma ação pedagógica criadora. Essa preocupação está no fato de detectar um grande problema na organização da escola:

Do ensino quase puramente dogmático, no qual a memória desempenha um grande papel, passa-se à fase criadora ou de trabalho autônomo e independente; da escola com disciplina de estudo imposta e controlada autoritariamente, passa-se a uma fase de estudo ou de trabalho profissional na qual a autodisciplina intelectual e a autonomia moral são teoricamente ilimitadas (GRAMSCI, 2000, p. 38).

Após essas duas fases da escola elementar é na Escola unitária que o aluno recebe uma formação de caráter científico com base no trabalho como princípio educativo. Essa última fase é decisiva, "na qual se tende a criar os valores fundamentais do "humanismo", a autodisciplina intelectual e a autonomia moral necessárias a uma posterior especialização, seja ela de caráter científico (estudos universitários), seja de caráter imediatamente prático-produtivo (indústria, burocracia, comércio, etc.) (GRAMSCI, 2000, p. 39)".

$\mathrm{Na}$ primeira fase da Escola unitária encontra-se o caráter pedagógico de escola ativa, cuja finalidade é a de elaborar os métodos e as formas de construção do conhecimento. Na segunda fase, o que norteia este caráter é o aspecto criador da escola, no qual o aluno, por conta própria ou com a assessoria de um professor, construirá seu próprio método de investigação e de conhecimento. Nessa escola,

“a aprendizagem ocorre, sobretudo, graças a um esforço espontâneo e autônomo do discente, e no qual o professor exerce apenas uma função de guia amigável, como ocorre ou deveria ocorrer na universidade. Descobrir por si mesmo uma verdade, sem sugestões e ajudas exteriores, é criação, mesmo que a verdade seja velha, e demonstra a posse do método; indica que, de qualquer modo, entrou-se na fase da maturidade intelectual, na

6o $\quad$ Notas sobre a escola unitária e trabalho no pensamento de Antonio Gramsci 
qual se podem descobrir verdades novas (GRAMSCI, 2000, p. 39-40)”.

Para Gramsci, só na fase da maturidade é que o aluno estaria pronto para fazer sua opção profissional. Aí estaria relacionado com a universidade, que teria, na sua formação, uma nova função:

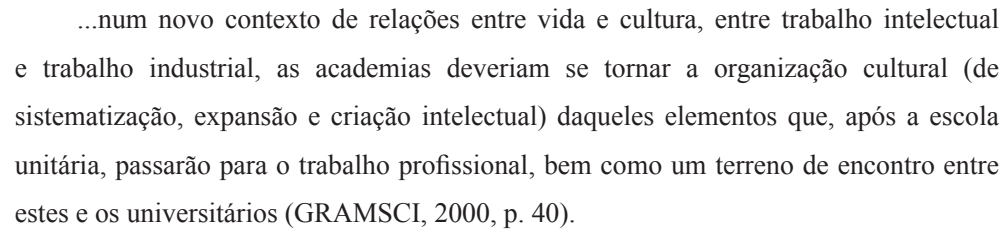

Como vemos, a organização escolar, no pensamento gramsciano, não pressupõe uma escola dualista, mas uma escola que dá organicidade às duas fases, cujo cerne está no seu método, que é o do trabalho como princípio educativo, identificado com o espaço do emprego diretamente produtivo, da ciência e da tecnologia.

Nesse sentido, o trabalho, para Gramsci, é essencialmente um elemento constitutivo do ensino, ou seja, um aspecto prático, que está inserido no seu conteúdo pelo método, viabilizando uma integração do trabalho com o momento educativo, cujo processo é totalmente autônomo e primário do ensino.

\section{Considerações finais}

O pensamento de Gramsci, no que se refere ao aspecto pedagógico e político-educacional do ensino, é de caráter revolucionário por centrar-se numa tendência democrática; intrinsecamente, não significa apenas que um operário manual se torne qualificado, mas que cada "cidadão" possa tornar-se "governante" e que a sociedade o ponha, ainda que "abstratamente", nas condições gerais de poder fazê-lo: a democracia política tende a fazer coincidir governantes e governados (no sentido de governo com o consentimento dos governados), assegurando a cada governado o aprendizado gratuito das capacidades e da preparação técnica geral necessária a essa finalidade (GRAMSCI, 2000, p. 50).

Gramsci acrescenta que, com o advento da escola unitária, ocorreria o início de novas relações entre trabalho intelectual e trabalho industrial não apenas na escola, mas em toda a vida social, cujo reflexo aconteceria em todos os organismos de cultura, transformando-os e emprestando-lhes um novo conteúdo.

Sendo assim, sua proposta de escola unitária não era isolada, mas gestada

cadernos cemarx, $\mathrm{n}^{\mathrm{O}} 5-2009 \quad 61$ 
no sabor da militância, cujas origens estavam no socialismo e no compromisso com a classe operária e que fazia parte de um projeto muito maior: construir uma nova ordem de relações sociais de produção, cuja finalidade era a contra-hegemonia.

Nesse sentido, a proposta de organização e funcionamento da Escola unitária tinha nos seus elementos básicos de relações pedagógicas, de conteúdos e de avaliação, a preocupação com a questão epistemológica, expressa na relação entre ciência, estrutura e superestrutura e sobre a relação entre sujeito e objeto do conhecimento. Essa organização mostrava-se pela unidade dialética entre atividades intelectuais e manuais, entre ciência e técnica, teoria e prática, cuja pretensão era contrariar a divisão social entre trabalho manual e trabalho intelectual. Propõe a tarefa de realizar a unidade entre teoria e ação sob a ótica do materialismo histórico-dialético, cuja finalidade era a articulação entre a técnica do trabalho e a sua base científica (politécnica). Ainda articulada com a formação para o trabalho, numa perspectiva politécnica, encontra-se, nessa escola, a formação básica necessária à construção de uma concepção de mundo e de formação política.

\section{Bibliografia}

ANDREUCCI, F. A Difusão e a vulgarização do marxismo. In: HOBSBAWN, E. História do marxismo. Rio de Janeiro: Paz e Terra 1992, vol. 2.

BAKUNIN, M. La instrucción integral. Madri: Scriptorius, 1979.

BELLUCCI, Maria; CILIBERTO, Michele. La scuola e la pedagogia del fascismo. Torino: Loescher Editore, 1978;

BORGHI, Lamberto. Educazione e autorità nell'Italia moderna. Firenze: La Nuova Italia editore, 1975.

CARMO, Jefferson Carriello do. A Reforma do Ensino Médio, de Giovanni Gentile e o Estado Fascista. In: QUAESTIO - Revista de Estudos de Educação. Sorocaba, SP, vol. $3 \mathrm{n}^{\circ} 1$, maio de 2001 .

DOMMANGET, Maurice. Os grandes socialistas e a educação: de Platão a Lenine. Lisboa: Europa-America, 1974.

GRAMSCI, Antonio. Cadernos do cárcere. Rio de Janeiro: Civilização Brasileira, 2000, vol. 2.

. Cadernos do cárcere. Rio de Janeiro: Civilização Brasileira, 2001, vol. 4.

62 Notas sobre a escola unitária e trabalho no pensamento de Antonio Gramsci 
Cartas do cárcere. Rio de Janeiro: Civilização Brasileira, 1996.

L'alternativa pedagogica. Firenze: La Nuova Itália, 1972.

MANACORDA, Alighiero Mario. Marx e la pedagogia moderna. Roma: Riuniti, 1966.

O princípio educativo em Gramsci. Porto Alegre: Artes Médicas, 1990.

MARX, Karl; ENGELS, Friedrich. Crítica da educação e do ensino. Lisboa: Moraes, 1978. Introdução e notas de Roger Dangeville.

NOSELLA, Paolo. A escola de Gramsci. Porto Alegre: Artes Médicas, 1992.

RAYNAUD, J. M; AMBAUVES, G. L' education libertaire. Paris: Spartacus, 1978.

TOMASI, Tina. Ideología libertari e formazione umana. Firenze: La nuova Italia, 1973.

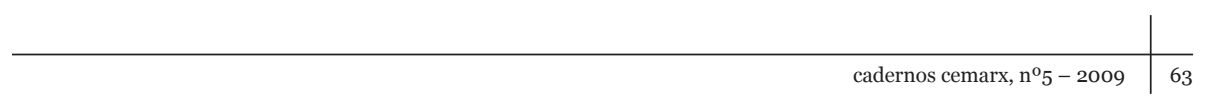

